\title{
DETECTION OF CONGENITAL HEART DEFECTS ON FETAL ANOMALY SCREENING : A SINGLE CENTRE EXPERIENCE OVER THREE YEARS
}

\author{
Emily Bar ${ }^{1}$, Yogen Singh ${ }^{1,2}$
}

\section{Background}

${ }^{1}$ School of Clinical Medicine, University of Cambridge, ${ }^{2}$ Cambridge University Hospitals NHS Foundation Trust, UK
Table 2 : Indications for administration of prostaglandin E1/E2

\begin{tabular}{|l|c|}
\hline Type of Congenital Heart Defect & No of cases (\%) \\
\hline Hypoplastic aortic arch & $3(33 \%)$ \\
\hline $\begin{array}{l}\text { Hypoplastic left heart syndrome } \\
\text { and coarctation of aorta }\end{array}$ & $1(11 \%)$ \\
\hline Coarctation of aorta & $1(11 \%)$ \\
\hline Double outlet right ventricle & $1(11 \%)$ \\
\hline Pulmonary atresia & $1(11 \%)$ \\
\hline $\begin{array}{l}\text { Tricuspid atresia and pulmonary } \\
\text { stenosis }\end{array}$ & $1(11 \%)$ \\
\hline $\begin{array}{l}\text { Absent pulmonary valve } \\
\text { syndrome }\end{array}$ & $1(11 \%)$ \\
\hline
\end{tabular}

\section{Figure 3 : Postnatal Interventions}

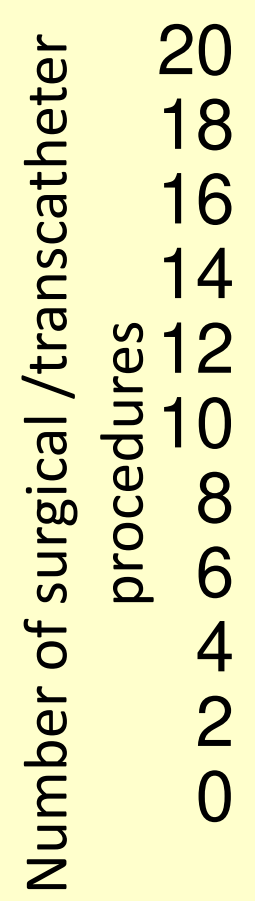
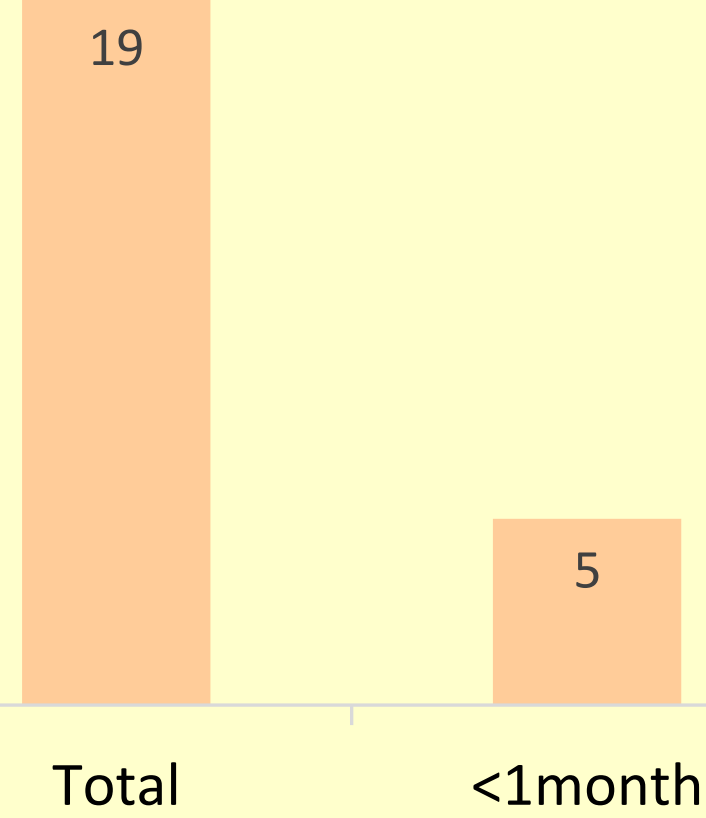

1month- 1 year

Time after birth

\section{Conclusions}

99 cases were referred for specialist fetal echocardiography (ECHO), of which $51 \%$ (50) were abnormal. Fetal ECHO diagnoses are shown in Figure 1.

> After diagnosis, most pregnancies continued (84\%), with 69\% of deliveries occurring at the Rosie Hospital.

> There were low levels of both prematurity and low birth weight ( $<2500$ grams), representing $31 \%$ of all births.

9 infants required prostaglandin E1/E2 postnatally, with the indications for this summarised in table 2 .

- Many infants needed surgical interventions shown in Figure 3, including 5 infants with critical CHD who required surgery soon after birth.

$>$ In our cohort, the 1 year survival rate was high at $92 \%$.
Half of the cases with a suspected CHD on FAS and referred for specialist fetal echocardiography had a congenital heart defect.

> Postnatal outcomes after early surgical intervention were good with a high survival rate for our cohort.

\section{References}

1. Singh, Y., McGeoch, L., 2016. Fetal Anomaly Screening for Detection of Congenital Heart Defects. J. Neonatal Biol. 5. https://doi.org/10.4172/2167$\underline{0897.100 \mathrm{e} 115}$

2. Singh, Y., Chee, Y.-H., Gahlaut, R., 2015. Evaluation of suspected congenital heart disease. Paediatr. Child Health 25, 7-12.

https://doi.org/10.1016/i.paed.2014.07.005

\section{Figure 1: Fetal ECHO diagnosis}
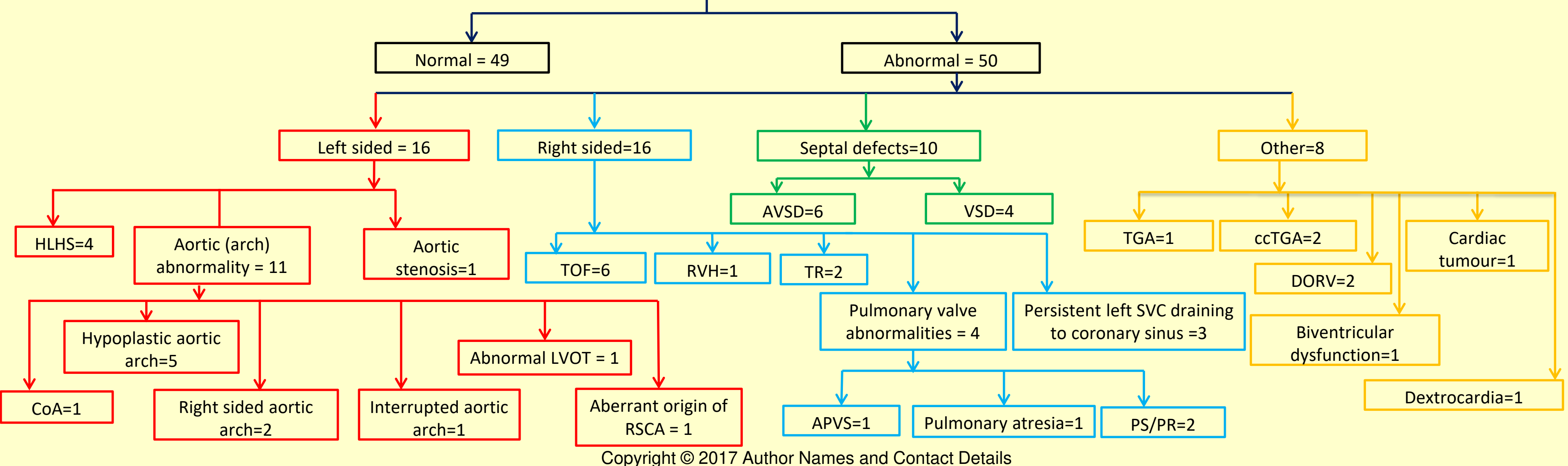